\title{
Efeito da extração de compostos fenólicos sobre a atividade antioxidante e antibacteriana in vitro de cogumelo-do-sol
}

\author{
Effect of extraction of phenolic compounds on the in vitro \\ antioxidant and antibacterial activity of sun mushroom
}

\author{
Flávia Santi Stefanello ${ }^{*}$, Carlos Pasqualin Cavalheiro', Fernanda Luísa Ludtke', \\ Mariana Santos da Silva', Liana Inês Guidolin Milani' ${ }^{1}$, Ernesto Hashime Kubota ${ }^{1}$
}

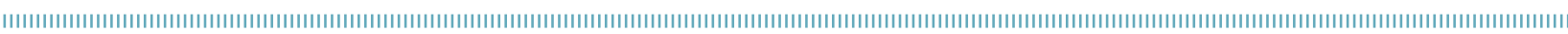

RESUMO: O cogumelo-do-sol (Agaricus blazei Murril) é amplamente consumido, por conta de suas propriedades medicinais. Este estudo teve como objetivo determinar a atividade antioxidante e antibacteriana in vitro dos extratos de cogumelo do sol, mediante diferentes tempos e temperaturas de extração. As amostras foram analisadas quanto à composição centesimal, determinação do teor de fenólicos totais e atividade antioxidante e antibacteriana in vitro. Os resultados demonstram que esse tipo de cogumelo aparece como um agente antioxidante potencial, obtendo-se melhores resultados na temperatura de $70^{\circ} \mathrm{C}$ durante 60 minutos de extração hidroetanólica. Esse extrato não aponta atividade antibacteriana para os micro-organismos em teste.

PALAVRAS-CHAVE: extratos; tempo; temperatura; agente antioxidante; micro-organismos.

\begin{abstract}
The sun mushroom (Agaricus blazei Murril) is widely consumed due its medicinal properties. This study aimed to determine in vitro antibacterial and antioxidant activities of sun mushroom, through different times and temperatures of extraction. The samples were analyzed for proximate composition, determination of total phenolic content and in vitro antibacterial and antioxidant activities. The results show that this kind of mushroom appears as a potential antioxidant agent, obtaining best results in the temperature of $70^{\circ} \mathrm{C}$ for 60 minutes in hydroethanol extraction. This extract shows no antibacterial activity for microorganisms under test.
\end{abstract}

KEYWORDS: extracts; time; temperature; antioxidant factor; microorganisms. 


\section{INTRODUÇÃO}

A implicação do estresse oxidativo na etiologia e na progressão de várias doenças, tais como o câncer e doenças cardiovasculares e neurodegenerativas, leva à sugestão de que os antioxidantes naturais podem ter benefícios à saúde como agentes profiláticos (Ferreira et al., 2009). Além disso, podem ser usados em aplicações dermatológicas, como cosméticos e também como suplementos na indústria de alimentos (Heleno et al., 2010).

Da mesma forma, extratos naturais com ação antimicrobiana apresentam-se como uma alternativa terapêutica, em razão de nas últimas décadas o uso irracional de antimicrobianos ter determinado o surgimento de cepas de micro-organismos multirresistentes, impulsionando a comunidade científica para a descoberta de novas opçóes desses agentes (Lund et al., 2009).

Nesse contexto, vários estudos têm evidenciado os potenciais antioxidantes e antimicrobianos de uma grande variedade de frutas e de vegetais. Consequentemente, compostos obtidos de fontes naturais, tais como grãos, sementes oleaginosas, especiarias, frutas, vegetais e cogumelos comestíveis, têm sido investigados (Asolini et al., 2006, VAz et al., 2011).

Os cogumelos são alimentos de alto valor nutricional, com baixos níveis energéticos e grandes quantidades de minerais, aminoácidos essenciais, vitaminas e fibras (Firenzuoli et al., 2008). Ademais, acumulam uma variedade de metabólitos secundários, tais quais compostos fenólicos, polipeptídeos, terpenos e esteroides possivelmente envolvidos em seus efeitos medicinais (Turkoglu et al., 2007). Perante esse cenário, a possibilidade de incluir cogumelos na dieta pode fornecer benefícios desejáveis para a saúde, para além da nutrição básica.

O cogumelo brasileiro Agaricus blazei Murill (AbM) provoca interesse da mídia e da comunidade científica, já que atingiu o topo do ranking dos melhores cogumelos medicinais (FIRENZUOLI et al., 2008). Conhecido como cogumelo-do-sol no Brasil, é consumido pela população como alimento e chá medicinal para combater diversas doenças (LuIz et al., 2003). O Brasil destaca-se como o maior produtor mundial de cogumelo-do-sol (AbM) este é espécie nativa do país —, apresentando condiçôes climáticas favoráveis (TomizAwa et al., 2007), de maneira que a expansão do cultivo do cogumelo tem sido verificada em várias regióes do país, visando abastecer o mercado internacional e nacional, o qual vem aumentando motivado pelo interesse da população brasileira em seus benefícios (MendonçA et al., 2005).

Esse cogumelo tem sido amplamente estudado nas áreas de ciência dos alimentos, medicina, biotecnologia e farmacologia (LARgeteau et al., 2011). Trabalhos têm relatado que o AbM apresenta atividade antibacteriana, como, por exemplo, na avaliação in vitro contra agentes patogênicos orais para humanos, tais como Streptococcus mutans (Lund et al., 2009), além de atividade antioxidante (SoAres et al., 2009), antidiabética (KIm et al., 2005), forte atividade imunoestimulante (Yuminamochi et al., 2007), bem como efeitos antitumorais e anticâncer (Yu et al., 2009), entre outros.
Os antioxidantes encontrados em cogumelos são principalmente compostos fenólicos, tendo sido quantificados em diferentes espécies encontradas em todo o mundo (VAZ et al., 2011). Quanto ao acúmulo desses compostos, o conteúdo de fenólicos totais e atividade antioxidante foram estimados e comparados em fases jovens e maduras de corpos de frutificação de AbM, não obtendo-se diferença entre elas (SoAREs et al., 2009). Por outro lado, a composiçáo nutricional e os componentes antioxidantes do AbM, incluindo os fenólicos totais, podem diminuir quando submetidos a tratamentos térmicos (Sun et al., 2011).

Em relação à atividade antibacteriana de compostos fenólicos, ela tem sido avaliada em estudos farmacêuticos e em alimentos. Alguns compostos fenólicos achados em plantas, tais como os de sálvia, alecrim, tomilho, lúpulo, coentro, cravo e manjericão, são conhecidos por possuírem efeitos antimicrobianos contra patógenos alimentares (AHN et al., 2007).

Dessa maneira, o objetivo deste artigo foi determinar a atividade antioxidante e antibacteriana in vitro dos extratos de cogumelo-do-sol (AbM) cultivado na região central do Rio Grande do Sul, mediante diferentes tempos e temperaturas de extração.

\section{MATERIAL E MÉTODOS}

As amostras de cogumelo-do-sol (AbM) foram fornecidas por um estabelecimento produtor localizado na cidade de Santa Maria, região central do Rio Grande do Sul, Brasil (coordenadas -29०41'03” +53048'25”), sob a forma de basidiocarpos imaturos previamente desidratados. Elas foram moídas em moinho analítico refrigerado $\left(4^{\circ} \mathrm{C}\right)$ (Quimis, modelo Q 298A21, Diadema, Brasil), classificadas em sistema de peneiras para partículas de $0,5 \mathrm{~mm}$ de diâmetro e acondicionadas em recipientes fechados, ao abrigo da luz e em freezer $\left(-12^{\circ} \mathrm{C}\right)$ até o momento de sua utilização.

Para a determinação da composição centesimal, as amostras de $\mathrm{AbM}$ foram submetidas à secagem em estufa a $105^{\circ} \mathrm{C}$ para a análise de umidade, para cinzas a $550^{\circ} \mathrm{C}$ e proteínas pelo método de Kjeldahl, segundo metodologia descrita pela Association of Official Analytical Chemists (AOAC, 2005). Os lipídios totais foram quantificados em conformidade com o método descrito por BLIGH; Dyer (1959), e todas essas análises foram conduzidas em triplicata.

Os extratos de $\mathrm{AbM}$ foram preparados do pó previamente moído, pesado (6 g) em um béquer e adicionado o álcool de cereais $80 \%(60 \mathrm{~mL})$ na proporção 1:10 (p/v). Em seguida, a mistura foi levada a dois banhos ultratermostatizados (Solab, modelo SL-152/10, Piracicaba, Brasil), um com temperatura de $50^{\circ} \mathrm{C}$ e outro com temperatura de $70^{\circ} \mathrm{C}$, e submetida à agitação constante por intermédio de agitador mecânico (Marconi MA-039, Piracicaba, Brasil), variando o tempo de extração em 15, 30 e 60 minutos. Depois disso, os seis extratos foram 
filtrados em papel-filtro e as soluçóes resultantes acondicionadas em frascos âmbar e armazenados em freezer $\left(-12^{\circ} \mathrm{C}\right)$ até $\mathrm{o}$ momento das análises, ressaltando que cada extração foi realizada em triplicata.

Para a estimativa de fenólicos totais, utilizou-se o reagente de Folin-Ciocalteu, descrito por Singleton et al. (1999). Em um baláo volumétrico, os extratos foram diluídos em álcool de cereais $80 \%$ na proporçáo 1:25 (v/v). Posteriormente, uma alíquota $(0,2 \mathrm{~mL})$ da soluçáo foi misturada a $1 \mathrm{~mL}$ de reagente de Folin-Ciocalteu 0,2 N. Aguardaram-se 8 min no escuro e adicionou-se $0,8 \mathrm{~mL}$ de solução de carbonato de sódio $\left(\mathrm{Na}_{2} \mathrm{CO}_{3}\right) 7,5 \%$. Após incubação à temperatura ambiente $\left(25^{\circ} \mathrm{C}\right)$ por 2 horas, a absorbância foi medida a $765 \mathrm{~nm}$ em espectrofotômetro (SP-220, Biospectro, São Paulo, Brasil).

A absorbância da amostra foi comparada com a curva padrão de ácido gálico (concentraçôes de 0 a $70 \mathrm{mg}$ de ácido gálico $100 \mathrm{~mL}^{-1}$ ), e aplicou-se a Equação 1:

$y=0,0109 x+0,0134$

Em que:

$\mathrm{Y}=$ absorbância,

$\mathrm{x}=$ concentração;

$\mathrm{R}^{2}=0,9986$. Coeficiente de determinação da equação, uma medida de ajustamento de um modelo estatístico linear generalizado em relação aos valores observados. $\mathrm{O} \mathrm{R}^{2}$ varia entre 0 e 1 , indicando em percentagem o quanto o modelo consegue explicar os valores alcançados.

O conteúdo total de fenólicos foi expresso em $\mathrm{mg}$ de fenólicos totais por g de extrato seco de cogumelo-do-sol (mg fenólicos totais/g cogumelo-do-sol), baseado na curva de calibração expressa em equivalentes de ácido gálico. As análises aconteceram em triplicata para os seis extratos hidroetanólicos de $\mathrm{AbM}$, e os valores são apresentados como a média ( \pm desvio padrão).

A atividade antioxidante dos compostos presentes nos extratos de cogumelo-do-sol foi determinada por meio da capacidade sequestrante do radical livre DPPH (2,2-difenil-1-picril-hidrazil), segundo metodologia descrita por Brand-Williams et al. (1995). A técnica consistiu na incubação por $30 \mathrm{~min}$ de $5 \mathrm{~mL}$ de solução etanólica $(80 \% \mathrm{v} / \mathrm{v})$ de DPPH $0,1 \mathrm{mM}$ com $5 \mathrm{~mL}$ de soluçôes contendo concentraçôes crescentes de extrato hidroetanólico de $\mathrm{AbM}(0,3 ; 0,6$; 1,$25 ; 2,5 ; 5 ; 10 ; 15 ; 20 ; 25 ; 30 ; 35$ e 40 mg.mL ${ }^{-1}$ ).

A soluçáo controle era composta de DPPH $0,1 \mathrm{mM} \mathrm{em}$ etanol $80 \%$ (v/v), e a solução branco, de solvente etanol $80 \%$ $(\mathrm{v} / \mathrm{v})$. Após incubação, foram realizadas as leituras das amostras em espectrofotômetro (SP-220, Biospectro, São Paulo, Brasil) em comprimento de onda de $517 \mathrm{~nm}$. A porcentagem de atividade antioxidante (AA\%) foi calculada mediante o percentual de captação do radical DPPH, conforme a Equação 2:
AA\% $=100-\left\{\left[\left(\right.\right.\right.$ Absorbância $_{\text {amostra }}-$ Abs. $\left.\left._{\text {branco }}\right) \times 100\right] \div$ Abs. $\left._{\text {control }}\right\}$

Depois disso, calculou-se a concentração necessária para capturar $50 \%$ do radical livre DPPH $\left(\mathrm{IC}_{50}\right)$ por intermédio de equação da reta obtida dos valores da absorbância (AA\%) das concentraçôes crescentes de extrato hidroetanólico de cogumelo-do-sol, substituindo o valor de Y por 50, obtendo-se o valor de $\mathrm{X}$ como a concentração correspondente. As análises foram realizadas em triplicata para os seis extratos hidroetanólicos de AbM.

Com base nos resultados da determinaçáo de fenólicos totais e atividade antioxidante in vitro, elegeu-se o extrato de melhor desempenho para a determinação da atividade antibacteriana in vitro. Com esse extrato, o solvente foi totalmente eliminado em rotaevaporador (Fisatom ${ }^{\circledR} 802$, Fisatom, São Paulo, Brasil) com vácuo de $-760 \mathrm{mmHg}$ e temperatura da água do banho a $60^{\circ} \mathrm{C}\left( \pm 1^{\circ} \mathrm{C}\right)$, e a parte sólida remanescente foi ressuspensa em água destilada esterilizada na concentração de $10 \mu \mathrm{g} \cdot \mu \mathrm{L}^{-1}$.

As cepas bacterianas foram adquiridas da coleção americana American Type Culture Collection (ATCC). A atividade antibacteriana do extrato de cogumelo-do-sol foi avaliada no tocante às bactérias gram-positivas: Staphylococcus aureus (ATCC 25.923), Bacillus cereus (ATCC 14.579) e Enterococcus faecalis (ATCC 19.433); e gram-negativas: Escherichia coli (ATCC 25.922), Pseudomonas aeruginosa (ATCC 10.145), Salmonella enterica subsp. enterica serovar Enteritidis (ATCC 13.076), Salmonella enterica subsp. enterica serovar Choleraesuis (ATCC 10.708), Salmonella enterica subsp. enterica serovar Typhimurium (ATCC 14.028) e Enterobacter aerogenes (ATCC 13.048).

Foi realizado o teste de difusão em disco, conforme os procedimentos descritos pelo National Committee for Clinical Laboratory Standards (NCCLS, 2003). Com culturas recentes dos micro-organismos em teste, foi preparada suspensáo em soluçáo fisiológica estéril ( $\mathrm{NaCl} 0,85 \%)$, a qual foi padronizada para 0,5 da escala McFarland. As suspensóes foram semeadas na superfície do ágar Mueller-Hinton, em placas de Petri, com auxílio de swab estéril. Posteriormente, discos de papel com $6 \mathrm{~mm}$ de diâmetro foram impregnados com $10 \mu \mathrm{L}$ dos extratos em teste e plaqueados no ágar previamente inoculado com o micro-organismo teste.

Para controle negativo, os discos de papel foram embebidos em água destilada esterilizada, e, para o controle positivo, usaram-se discos com $30 \mu \mathrm{g}$ de cloranfenicol. Após $24 \mathrm{~h}$ de incubação a $36^{\circ} \mathrm{C}$, foi medido o diâmetro dos halos de inibição de crescimento nas placas.

Obtiveram-se os resultados como médias de análises em triplicata. Os dados foram submetidos à análise de variância (ANOVA) e regressão por meio do programa estatístico Statistical Package for the Social Sciences (SPSS) 17.0. Quando os dados não se ajustaram aos modelos de regressão, as médias foram comparadas pelo teste de Tukey, utilizando nível de significância de 5\%. 


\section{RESULTADOS E DISCUSSÃO}

A composição centesimal do cogumelo-do-sol desidratado está representada na Tabela 1 . O teor de proteína bruta foi de $31,31 \mathrm{~g} \%( \pm 0,006)$ e o de lipídios foi de $4,05 \mathrm{~g} \%$ $( \pm 0,007)$, configurando elevado teor de proteínas e baixo de lipídeos, não diferindo de outros cogumelos comestíveis (Agahar-Murukar; Subbulakshmi, 2005). Os cogumelos frescos chegam a apresentar umidade inicial de 85 a $95 \%$ e, quando desidratados, de 5 a 20\% (Sampaio; Queiroz, 2006), valores confirmados pelo resultado encontrado neste estudo, em que o valor da umidade do cogumelo desidratado foi de $5,86 \mathrm{~g} \%( \pm 0,001)$.

Os cogumelos desidratados também são excelente fonte de fibras alimentares (Tabela 1), o que é representado pelo valor de $29,79 \mathrm{~g} \%( \pm 0,006)$, além de minerais $(6,91 \pm 0,001 \mathrm{~g} \%)$, corroborando com outros resultados da literatura (CHANG, 2008). Assim, diversos estudos, assim como este, têm comprovado que o valor nutritivo de cogumelo-do-sol é de qualidade para uma dieta balanceada, indicando a sua utilizaçáo como alimento funcional, o que vem aumentando expressivamente nos últimos anos.

Por outro lado, a busca de um método de extraçáo de compostos fenólicos prático e eficiente é um processo constante nas avaliaçôes de compostos bioativos, em que diversos parâmetros devem ser observados, podendo ser influenciados pelo solvente, pelo tempo e pelas altas temperaturas (Carvalho et al., 2007).

Os valores de fenólicos totais do extrato hidroetanólico do AbM — expresso em mg fenólicos totais/g cogumelo-do-sol desidratado - estáo representados na Figura 1A, considerando as variaçóes de tempo e temperatura empregadas durante a extração.

De acordo com os resultados (Fig. 1A), pode-se observar que o tempo de extraçáo de $60 \mathrm{~min}$ foi o que apresentou nos cogumelos o maior teor de fenólicos totais para ambas as temperaturas aplicadas $\left(50^{\circ}\right.$ e $\left.70^{\circ} \mathrm{C}\right)$, em relação aos tempos de 15 e 30 min de extração.

Portanto, levando-se em conta o tempo de extraçáo de 60 min, os teores de compostos fenólicos totais não diferiram entre as temperaturas de $50(4,41 \pm 0,533)$ e de $70^{\circ} \mathrm{C}$

Tabela 1. Composição centesimal do cogumelo-do-sol (Agaricus blazei Murril) desidratado.

\begin{tabular}{lc} 
Composição centesimal & g (\%) \\
\hline Umidade & $5,86 \pm 0,001$ \\
\hline Proteína & $31,31 \pm 0,006$ \\
\hline Cinzas & $6,91 \pm 0,001$ \\
\hline Gordura & $4,05 \pm 0,007$ \\
\hline Fibra & $29,79 \pm 0,006$ \\
\hline
\end{tabular}

Médias \pm desvio padrão de análises em triplicata.
$(5,34 \pm 0,048)$ aplicadas. Em concordância com os resultados obtidos, a melhor condição de tempo de extração de compostos antioxidantes do $\mathrm{AbM}$ foi $60 \mathrm{~min}$, independentemente da temperatura utilizada (MourÁo et al., 2011).

Foi encontrado valor de $2,55 \mathrm{mg}$ de fenólicos totais/g de extrato de cogumelo-do-sol utilizando solvente metanol $50 \%$ com tempo de extração de 24 horas à temperatura ambiente (Sun et al., 2011), enquanto, com o solvente metanol $70 \%$ no mesmo tempo de extração ( 24 horas) à temperatura ambiente, foram achados valores de 0,83 a 42,21 mg de fenólicos totais/g de extrato para diferentes cogumelos comestíveis (Pleurotus porrigens, Hygrocybe conica, Xerula furfuracea, Schizophyllum commune, Polyporus tenuiculus e Pleurotus florida), representando oscilação bastante acentuada, conforme cada tipo de cogumelo avaliado (Wong; Chye, 2009).

As variaçóes alcançadas nos teores dos compostos fenólicos totais ocorrem por conta das diversas variaçôes nas condições da extração, como tipo e concentração de solvente, proporção de amostra-solvente, temperatura e tempo de extração (Mata et al., 2007). As diferenças de valor também podem estar relacionadas a fatores como o clima e o substrato de cultivo, além do tipo de cogumelo, entre outros (SOAREs et al., 2009).

Os resultados obtidos na determinação da atividade antioxidante in vitro dos extratos de cogumelo-do-sol demonstrados
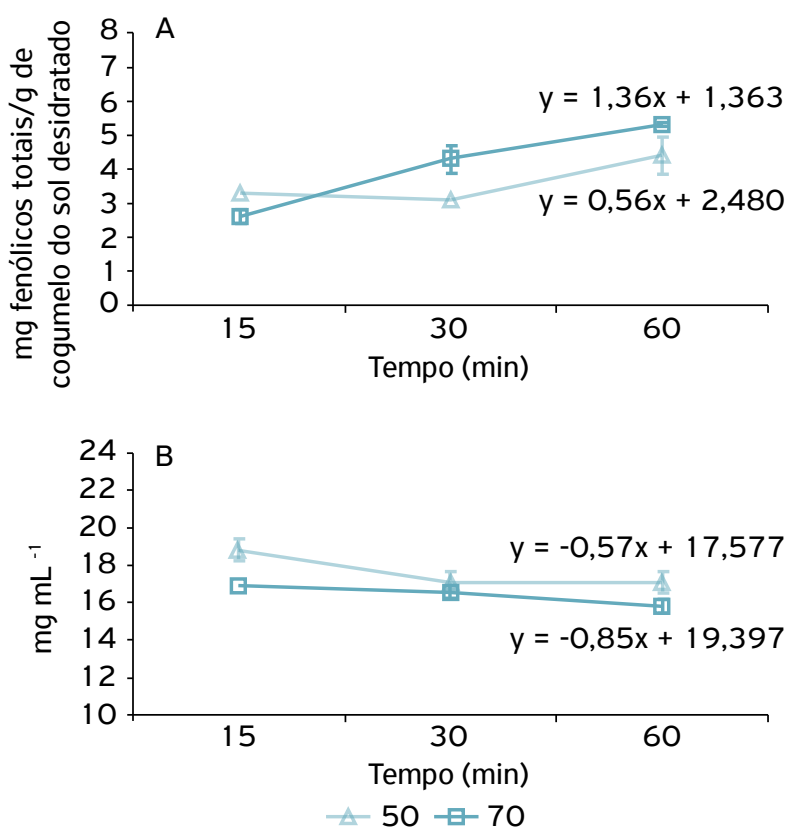

Figura 1. Fenólicos totais (A) e atividade antioxidante in vitro representada pela concentração necessária para capturar $50 \%$ do radical livre 2,2-difenil-1-picril-hidrazil (DPPH) - IC5O (B) de extratos hidroetanólicos de cogumelo-do-sol obtidos em temperatura de $50^{\circ}$ e $70^{\circ} \mathrm{C}$ nos tempos de 15,30 e 60 min de extração. 
por meio da concentração capaz de sequestrar $50 \%$ do radical $\mathrm{DDPH}\left(\mathrm{IC}_{50}\right)$ estão representados na Figura $1 \mathrm{~B}$.

Quanto menor o valor de $\mathrm{IC}_{50}$, maior a atividade antioxidante do extrato, já que esse valor representa a quantidade de extrato necessária para reduzir em 50\% a atividade do radical livre, de forma que valores de $\mathrm{IC}_{50}$ acima de $25 \mathrm{mg} \mathrm{mL}^{-1}$ são considerados de baixo potencial antioxidante (CAmpos et al., 2005).

Os resultados (Fig. 1B) para as análises in vitro realizadas com os extratos de cogumelo-do-sol demonstraram valores de $\mathrm{IC}_{50}$ menores para a temperatura de $70^{\circ} \mathrm{C}$ independentemente dos tempos de extraçáo. Dessa forma, tendo em vista essa temperatura de extração, o valor mais baixo do $\mathrm{IC}_{50}$ foi para o tempo de $60 \mathrm{~min}\left(15,80 \mathrm{mg} \mathrm{mL}^{-1}\right)$.

Nessas condiçóes a atividade antioxidante aumentou com a elevação da temperatura de extração de $50^{\circ}$ para $70^{\circ} \mathrm{C}$, diferindo de outros trabalhos, em que o tratamento térmico reduziu a quantidade de fenólicos totais, bem como alterou os tipos e a quantidade relativa desses compostos (Sun et al., 2011). Entretanto, esta pesquisa corrobora com resultados de outros estudos, que determinaram a temperatura de $70^{\circ} \mathrm{C}$ como o limite máximo a ser empregado no processo extrativo para evitar a degradação, a polimerização e a oxidação de compostos fenólicos, fatores que resultariam na redução destes (Реixoto Sobrinho et al., 2010).

A capacidade antioxidante do cogumelo-do-sol foi avaliada anteriormente apresentando valor de $\mathrm{IC}_{50}$ de $3 \mathrm{mg}$ de extrato $\mathrm{mL}^{-1}$ (SoARes et al., 2009), representando capacidade antioxidante mais eficiente do que a constatada neste trabalho. Todavia, para cogumelos selvagens comestíveis, classificação que engloba o cogumelo estudado, a concentração de extrato necessária para capturar $50 \%$ do radical livre DPPH $\left(\mathrm{IC}_{50}\right)$ foi em média de $20 \mathrm{mg}$ de extrato $\mathrm{mL}^{-1}$ (Wong; Chye, 2009), representando um valor aproximado ao encontrado, de $17,13 \mathrm{mg}$ de extrato $\mathrm{mL}^{-1}$, considerando condiçôes de extração semelhantes.

Cabe salientar que diferentes autores têm apresentado valores de $\mathrm{IC}_{50}$ de antioxidantes naturais com grandes diferenças, dificultando a comparação dos resultados, provavelmente pelo fato de haver diferenças nas metodologias utilizadas para a elaboração de extratos.

$\mathrm{O}$ extrato hidroetanólico de cogumelo-do-sol avaliado nas concentraçóes de 1, 2 e 4\% não apresentou atividade antibacteriana sobre Staphylococcus aureus, Bacillus cereus, Enterococcus faecalis, Escherichia coli, Pseudomonas aeruginosa, Salmonella enterica subsp. enterica serovar Enteritidis, Salmonella enterica subsp. enterica serovar Choleraesuis, Salmonella enterica subsp. enterica serovar Typhimurium nem Enterobacter aerogenes, segundo o teste de difusão em disco. $\mathrm{Na}$ Figura 2, pode-se observar o halo de inibição do crescimento microbiano em relação ao disco impregnado com

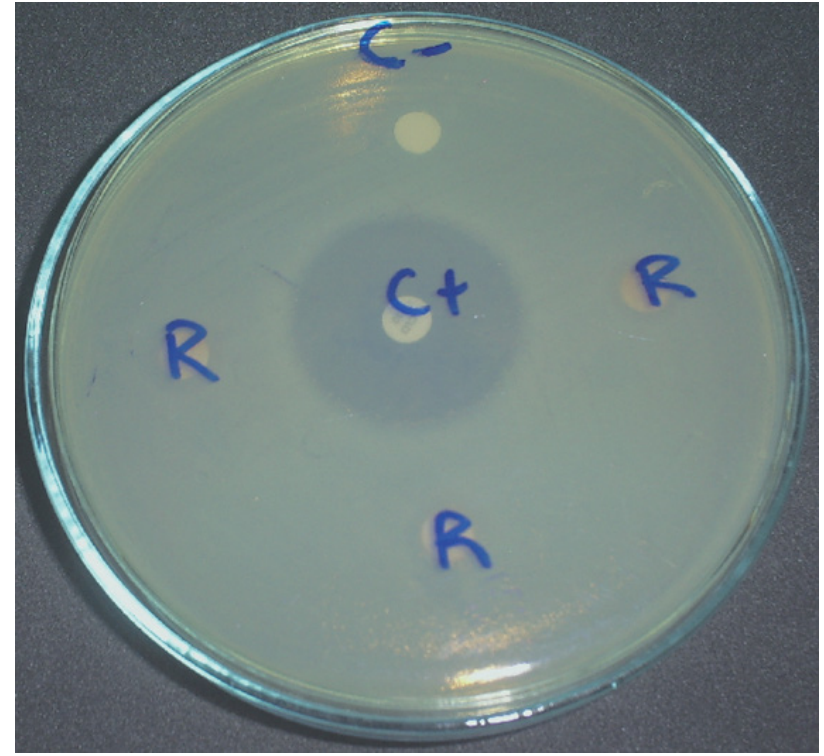

Figura 2. Placa de Petri com halo de inibição do crescimento microbiano em relação ao disco impregnado com cloranfenicol $30 \mu \mathrm{g}$ (controle positivo, $\mathrm{C}+$ ), discos com o extrato em três repetições ( $100 \mu \mathrm{g}$ cada disco, $\mathrm{R}$ ) e disco com água destilada (controle negativo, C-).

cloranfenicol $30 \mu \mathrm{g}(\mathrm{C}+)$, utilizado como controle positivo no teste de difusão em disco.

$\mathrm{Na}$ avaliação da atividade antimicrobiana de extratos metanólicos de três espécies de Agaricus, os autores verificaram que as bactérias gram-positivas foram mais sensíveis ao extrato de cogumelo do que as bactérias gram-negativas quando empregado $200 \mu \mathrm{g}$ de cogumelo (ÖZTüRK et al., 2011), o que náo ficou evidente neste trabalho quando utilizado $100 \mu \mathrm{g}$ de cogumelo.

Os resultados obtidos no teste de difusão em disco sugerem ausência de atividade antibacteriana das substâncias presentes no extrato hidroetanólico de $\mathrm{AbM}$, ou pequena concentração, não atingindo a concentração inibitória mínima para os micro-organismos em teste.

\section{CONCLUSÕES}

Nas condiçóes deste estudo, o extrato hidroetanólico de cogumelo-do-sol (Agaricus blazei Murril) apresentou-se como um potencial agente antioxidante in vitro. $\mathrm{O}$ melhor resultado de extração foi obtido em temperatura de $70^{\circ} \mathrm{C}$ durante $60 \mathrm{~min}$, apresentando-se numa relação diretamente proporcional entre o conteúdo de fenólicos totais e a capacidade antioxidante in vitro. $\mathrm{O}$ mesmo extrato náo apontou atividade antibacteriana para os micro-organismos em teste. 
AGAHAR-MURUKAR, D.; SUBBULAKSHMI, G. Nutritional value of edible wild mushrooms collected from the Khasi hills of Meghalaya. Food Chemistry, v.89, n.4, p.599-603, 2005. DOI: 10.1016/j. foodchem.2004.03.042

AHN, J.; GRÜN, I.U.; MUSTAPHA, A. Effects of plant extracts on microbial growth, color change, and lipid oxidation in cooked beef. Food Microbiology, v.24, n.4, p.7-14, 2007. DOI: $10.1016 / \mathrm{j} . \mathrm{fm} .2006 .04 .006$

ASOLINI, F.C.; TEDESCO, A.M.; CARPES, S.T. Atividade antioxidante e antimicrobiana dos compostos fenólicos dos extratos de plantas usadas como chás. Brazilian Journal of Food Technology, v.9, n.3, p.209-215, 2006.

ASSOCIATION OFFICIAL ANALYTICAL CHEMISTS (AOAC). Official methods of analysis of the Association Official Analytical Chemists. 18th.ed. Gaithersburg, Maryland, 2005.

BLIGH, E.C.; DYER, W.J. A rapid method of total lipid extraction and purification. Canadian Journal of Biochemistry and Physiology, v.37, n.8, p.911-917, 1959.

BRAND-WILLIAMS, W.; CUVELIER, M.E.; BERSET, C. Use of a free radical method to evaluate antioxidant activity. Lebensm Wiss Technology, v.28, p.25-30, 1995.

CAMPOS, L.M.A.S.; MICHIELIN, E.M.Z.; DANIELSKI, L.; FERREIRA, S.R.S. Experimental data and modeling the supercritical fluid extraction of marigold (Calendula officinalis) oleoresin. Journal of Supercritical Fluids, v.34, n.2, p.163-170, 2005. DOI: $10.1016 /$ j.supflu.2004.11.010

CARVALHO, J.C.T.; GOSMANN, G.; SCHENKEL, E.P. Compostos fenólicos simples e heterosídeos. In: SIMÕES, M.O.; SCHENKEL, E.P.; GOSMANN, G.; MELLO, J.C.P.; MENTZ, L.A.; PETROVICK, P.R. (Orgs.). Farmacognosia da planta ao medicamento. 3.ed. Porto Alegre: UFRGS; Florianópolis: UFSC, 2007.

CHANG, S.T. Overview of mushroom cultivation and utilization as functional foods. In: CHEUNG, P.C.K. Mushrooms as functional foods. Nova Jersey: Wiley-Interscience, 2008. p.1-33.

FERREIRA, I.C.F.R.; BARROS, L.; ABREU, R.M.V. Antioxidants in wild mushrooms. Current Medicinal Chemistry, v.16, n.12, p.1543-1560, 2009.

FIRENZUOLI, F.; GORI, L.; LOMBARDO, G. The medicinal mushroom Agaricus blazei Murrill: review of literature and pharmaco-toxicological problems. Evidence-Based Complementary and Alternative Medicine, v.5, n.1, p.3-15, 2008. DOI: $10.1093 /$ ecam/nem007

HELENO, S.A.; BARROS, L.; SOUSA, M.J.; MARTINS, A.; FERREIRA, I.C.F.R. Tocopherols composition of Portuguese wild mushrooms with antioxidant capacity. Food Chemistry, v. 119 , n.4, p.1.443-1.450, 2010 . DOI: $10.1016 /$ j. foodchem.2009.09.025
KIM, Y.W.; KIM, K.H.; CHOI, H.J; LEE, D.S. Anti-diabetic activity of beta-glucans and their enzymatically hydrolyzed oligosaccharides from Agaricus blazei. Biotechnology Letters, v.27, n.7, p.483-487, 2005. DOI: $10.1007 / \mathrm{s} 10529-005-2225-8$

LARGETEAU, M.L.; LLARENA-HERNÁNDEZ, R.C.; REGNAULT-ROGER, C.; SAVOIE, J.M. The medicinal Agaricus mushroom cultivated in Brazil: biology, cultivation and non-medicinal valorization. Applied Microbiology and Biotechnology, v.92, p.897-907, 2011. DOI: $10.1007 / \mathrm{s} 00253-011-3630-7$

LUIZ, R.C.; JORDÃO, B.Q.; EIRA, A.F.; RIBEIRO, L.R.; MANTOVANI, M.S. Mechanism of anticlastogenicity of Agaricus blazei Murill mushroom organic extracts in wild type $\mathrm{CHO}$ (K1) and repair deficient (xrs5) cells by chromosome aberration and sister chromatid exchange assays. Mutation Research, v.528, n. 1-2, p.75-79, 2003. DOI: 10.1016/SOO27-5107(03)00098-8

LUND, R.G.; DEL PINO, F.A.B.; SERPA, R.; NASCIMENTO, J.S.; SILVA, V.M.; RIBEIRO, G.A.; ROSALEN, P.L. Antimicrobial activity of ethanol extracts of Agaricus brasiliensis against mutans streptococci. Pharmaceutical Biology, v.47, p.910-915, 2009. DOI: $10.1080 / 13880200902950801$

MATA, A.T.; PROENÇA, C.; FERREIRA, A.R.; SERRALHEIRO, M.L.M.; NOGUEIRA, J.M.F. Antioxidant and antiacetylchoalonesterase activities of five plants used as Portuguese food spices. Food Chemistry, v.103, n.3, p.778-786, 2007. DOI: http://dx.doi. org/10.1016/j.foodchem.2006.09.017

MENDONÇA, M.; KASUYA, M.C.; CADORIN, A.; VIEIRA, A.J. Mushroom for a living: Agaricus blazei cultivation for a living in Brazil. In: Shiitake cultivation. Part II. Mushroom for better life. Seoul: MushWorld, 2005. p.208-218. (Mushroom growers' handbook, 2).

MOURÃO, F.; UEMO, S.H.; TAKEMURA, O.S.; LINDE, G.A.; COLAUTO, N.B. Antioxidant activity of Agaricus brasiliensis basidiocarps on different maturations phases. Brazilian Journal of Microbiology, v.42, n.1, p.197-202, 2011 . DOI: 10.1590/ S1517-83822011000100024

NACIONAL COMMITTEE FOR CLINICAL LABORATORY STANDARDS (NCCLS). Performance standards for antimicrobial disk susceptibility tests. 8.ed. Wayne: NCCLS, 2003. 58 p.

ÖZTÜRK, M.; DURU, M.E.; KIVRAK, S.; MERCAN-DOĞAN, N.; TÜRKOGLU, A.; ÖZLER, M.A. In vitro antioxidant, anticholinesterase and antimicrobial activity studies on three Agaricus species with fatty acid compositions and iron contents: a comparative study on the three most edible mushrooms. Food and Chemical Toxicology, v.49, n.6, p.1353-1360, 2011. DOI: $10.1016 /$ j.fct.2011.03.019

PEIXOTO SOBRINHO, T.J.S.; GOMES, T.L.B.; CARDOSO, K.C.M.; AMORIM, E.L.C.; ALBUQUERQUE, U.P. Otimização de metodologia analítica para o doseamento de flavonoides de Bauhinia cheilantha (Bongard) Steudel. Química Nova, v.33, n.2, p.288-291, 2010. DOI: 10.1590/SO100-40422010000200011 
SAMPAIO, S.M.; QUEIROZ, M.R. Influência do processo de secagem na qualidade do cogumelo Shiitake. Engenharia Agrícola, Jaboticabal, v.26, n.2, p.570-577, 2006. DOI: 10.1590/ S0100-69162006000200027

SINGLETON, V.L.; ORTHOFER, R.; LAMUELA-RAVENTOS, R.M. Analysis of total phenols and other oxidation substrates and antioxidants by means of Folin-Ciocalteau reagent. Methods Enzymol, v.299, p.152-178, 1999. DOI: 10.1016/SO076-6879(99)99017-1

SOARES, A.A.; SOUZA, C.G.M.; DANIEL, F.M.; FERRARI, G.P.; COSTA, S.M.G.; PERALTA, R.M. Antioxidant activity and total phenolic content of Agaricus brasiliensis (Agaricus blazei Murril) in two stages of maturity. Food Chemistry, v. 112 , n.4, p.775-781 2009. DOI: 10.1016/j.foodchem.2008.05.117

SUN, L.; ZHUANG, Y.; BAI, X. Effects of boiling and microwaving treatments on nutritional characteristics and antioxidant activities of Agaricus blazei Murril. International Journal of Food Science and Technology, v.46, n.6, p.1209-1215, 2011. DOI: $10.1111 /$ j. 1 365-2621.2011.02602.x

TOMIZAWA, M.M.; SOUZA, E.D.; ASSIS, L.J.; GOMIDE, P.H.O. SANTOS, J.B. Variabilidade genética de isolados do cogumelo Agaricus blazei por meio de marcadores RAPD. Ciência e Agrotecnologia, v.31, n.4, p.1.242-1.249, 2007.DOI: 10.1590/ S1413-70542007000400045
TURKOGLU, A.; DURU, E.M.; MERCAN, I.K.; GEZER, K. Antioxidant and antimicrobial activities of Laetiporus sulphureus (Bull.) Murrill. Food Chemistry, v.101, n. 1, p.267-273, 2007. DOI: 10.1016/j. foodchem.2006.01.025

VAZ, J.A; BARROS, L.; MARTINS, A.; MORAIS, J.S.; VASCONCELOS, M.H.; FERREIRA, I.C.F.R. Phenolic profile of seventeen Portuguese wild mushrooms. LWT - Food Science and Technology, v.44, n. 1, p.343-346, 2011 . DOI: 10.1016/j. Iwt.2010.06.029

WONG, J.Y.; CHYE, F.Y. Antioxidant properties of selected tropical wild edible mushrooms. Journal of Food Composition and Analysis, v.22, n.4, p.269-277, 2009. DOI: 10.1016/j. jfca.2008.11.021

YUMINAMOCHI, E.; KOIKE, T.; TAKEDA, K.; HORIUCHI, I.; OKUMURA, K. Interleukin-12- and interferon-gamma-mediated natural killer cell activation by Agaricus blazei Murill. Immunology, v.121, n.12, p.197-206, 2007. DOI: $10.1111 /$ j.1365-25 67.2006.02558.x

YU, C.H.; KAN, S.F.; SHU, C.H.; LU, T.J.; SUN-HWANG, L.; WANG, P.S. Inhibitory mechanisms of Agaricus blazei Murill on the growth of prostate cancer in vitro and in vivo. The Journal of Nutritional Biochemistry, v.20, n.10, p.753-764, 2009. DOI: 10.1016/j. jnutbio.2008.07.004 